OPEN ACCESS

Edited by:

Dennis Murray,

Trent University, Canada

Reviewed by:

Paul Grant,

Department of Fisheries and Ocean

Canada, Canada

Pavel Kindlmann,

Charles University, Czechia

*Correspondence:

Almo Farina

almo.farina@uniurb.it

Specialty section:

This article was submitted to

Population, Community,

and Ecosystem Dynamics,

a section of the journal

Frontiers in Ecology and Evolution

Received: 27 July 2021

Accepted: 23 November 2021

Published: 20 December 2021

Citation:

Farina A, Mullet TC

Bazarbayeva TA, Tazhibayeva T,

Bulatova D and Li P (2021)

Perspectives on the Ecological Role

of Geophysical Sounds.

Front. Ecol. Evol. 9:748398.

doi: 10.3389/fevo.2021.748398

\section{Perspectives on the Ecological Role of Geophysical Sounds}

\author{
Almo Farina ${ }^{1 *}$, Tim C. Mullet ${ }^{2}$, Tursynkul A. Bazarbayeva ${ }^{3}$, Tamara Tazhibayeva ${ }^{3}$, \\ Diana Bulatova ${ }^{3}$ and Peng $\mathrm{Li}^{4}$
}

\begin{abstract}
${ }^{1}$ Department of Pure and Applied Sciences, Urbino University, Urbino, Italy, ${ }^{2}$ Kenai Fjords National Park, U.S. National Park Service, Seward, AK, United States, ${ }^{3}$ Department of UNESCO on Sustainable Development, Al-Farabi Kazakh National University, Almaty, Kazakhstan, ${ }^{4}$ Division of Sleep and Circadian Disorders, Brigham and Women's Hospital, Harvard Medical School, Boston, MA, United States
\end{abstract}

Humans categorize unwanted sounds in the environment as noise. Consequently, noise is associated with negative human and ecological values, especially when it is derived from an anthropogenic source. Although evidence confirms that many machine-generated anthropogenic sounds have negative impacts on animal behavior and communication, natural sources of non-biological sound, such as wind, rain, running water, and sea waves (geophonies) have also been categorized as noise and are frequently dismissed or mischaracterized in acoustic studies as an outside factor of acoustic habitats rather than an integrated sonic component of ecological processes and species adaptations. While the proliferation of machine-generated sound in the Biosphere has become an intrusive phenomenon in recent history, geophony has shaped the Earth's sonic landscapes for billions of years. Therefore, geophonies have very important sonic implications to the evolution and adaptation of soniferous species, forming essential ecological and semiotical relationships. This creates a need to distinguish geophonies from machine-generated sounds and how species respond to each accordingly, especially given their acoustic similarities in the frequency spectrum. Here, we introduce concepts and terminology that address these differences in the context of ecoacoustics. We also discuss how Acoustic Complexity Indices (ACls) can offer new possibilities to quantifiably evaluate geophony in relation to their sonic contest.

Keywords: ecoacoustics, geophonies, noise, natural quiet, sonic signature

\section{INTRODUCTION}

Environmental sounds represent an important phenomenon that is integral to the functioning of ecological systems (Gage and Farina, 2017). Natural and human-generated sounds are deeply interwoven with the ecological processes and patterns driven by biotic and abiotic relationships (Sueur and Farina, 2015; Gage and Farina, 2017). As such, these sounds are integrated elements within semiotic interactions, as well as measurable indicators of ecological relationships and environmental degradation (Krause et al., 2011; Pijanowski et al., 2011; Farina, 2014; Fuller et al., 2015; Krause and Farina, 2016; Mullet et al., 2016).

The global decline of biodiversity in the wake of expanding human development (United Nations [UN], 2019b), resource depletion (United Nations [UN], 2019a), and climate change (IPCC, 2021) has driven ecologists to examine these relationships in traditional and novel ways. The emerging field of Ecoacoustics has revealed the important role sound plays in ecological 
relationships (Farina, 2014; Farina and Gage, 2017). These discoveries have expanded the field of ecology to new frontiers with an increasing degree of relevance in the scientific community (Xie et al., 2020). Accordingly, ecoacoustics has added to the growing literature on bioacoustics, environmental impacts of machine-generated sounds on wildlife communities (Shannon et al., 2016; Jerem and Mathews, 2021), and the use of sounds as proxies for assessing environmental quality (Botteldooren et al., 2006; Booi and van den Berg, 2012).

A great deal of work has focused on the impact machinegenerated sounds (technophony) have on soniferous species (Jerem and Mathews, 2021). As a result, it is a common practice in acoustic studies to separate the different sound sources of biophony (e.g., bird songs and calls) from the technophonic sounds of machines where biophonies are the singular soundscape component evaluated against the presence of "noise." Noise, in this context, is generally considered the technophony of every machine-generated signal that interferes with animal communication and/or causes a change in animal behavior and/or physiology (Tafalla and Evans, 1997; Barber et al., 2010). Technophony is an emergent component of many sonic environments and has a significant influence on the occupancy and habitat selection of many species (Mullet et al., 2017a).

The study of noise impacts on animals follows a long-standing "human-vs.-nature" paradigm that emphasizes the separation of human actions from non-human, natural processes (Barr, 1972). However, it is not unusual for the natural phenomenon of geophony (e.g., geophysical sounds generated by wind, rain, running water, sea waves) to be lumped together with technophony as "noise" (Klump, 1996; Brumm, 2010; Koper and Plön, 2012; Luther and Gentry, 2013; Bunkley et al., 2015) despite the differential semiotic interpretations wild animals likely have of these two sonic components. In these cases, animal sounds (biophony) are evaluated against a more generic "background noise" (Luther and Gentry, 2013), "ambient noise" (Ryan and Brenowitz, 1985), or "environmental noise" (Kight and Swaddle, 2011), often associated with geophysical sounds. Currently, the sonic-ecological relevance of geophonies remain ambiguous in acoustic studies even though they are present in every terrestrial and aquatic environment in some form. Furthermore, there exists a confusing characterization of geophony as having both negative acoustic qualities in the form of "environmental noise" and positive acoustic qualities in the form of "natural quiet" (Mace et al., 2004; Manning et al., 2007, 2018; Lynch et al., 2011). The indistinction between geophony and noise, along with the lack of reporting the role geophony plays in bioacoustics and ecoacoustics studies, are leaving an unavoidable gap in our understanding of sonic-ecological relationships.

In this paper, we clarify the distinction between noise, geophony, and natural quiet in order to establish a common language that serves to mitigate continued confusion in the ecoacoustics literature. We also discuss the active role geophony plays in ecological processes and the relevance of geophony in species evolution, communication, and habitat selection. We emphasize the need to establish clear reasoning for combining or separating geophonies from technophonies in acoustic studies and provide an example of how acoustic indices can be useful tools to address geophony in acoustic analysis.

\section{ETYMOLOGY OF NOISE, GEOPHONY, AND NATURAL QUIET IN ECOACOUSTICS}

As with any new field of science, there is a need to establish an etymology to properly describe its subjects and theoretical philosophies while building upon and/or clarifying language commonly used and accepted in the literature. Ecoacoustics has put a great deal of effort into creating a cohesive vocabulary of terms that explicitly describes its subjects and theories (Sueur and Farina, 2015; Mullet et al., 2017a; Farina et al., 2021a; Farina and Li, 2021). This endeavor has been an evolving process as new ideas, hypotheses, and philosophies emerge. Our intent here is to clarify, introduce, and define terminology associated with noise and geophony for future ecoacoustic investigations.

\section{Noise and Technophony}

The origins of the word noise are largely uncertain, but at least date back to the Greek period. Linguistically, noise is a derivative of the Greek word "nautes" (sailor) and the Latin word "nausea," meaning disgust, annoyance, discomfort, or seasickness. Other origins have come from the Latin "noxia," which means hurting, injury, or damage. Contemporarily, noise is broadly defined as unwanted sound. Yet, more specifically, the Oxford English Dictionary describes noise as a sound that is especially loud or unpleasant, causing disturbance or confusion among other sounds, and contains no meaningful information. Noise is inherently negative and subjectively defined by human perception.

Notably, the linguistic roots of noise from the pre-industrial age clearly indicate that unwanted sounds were not originally associated with the sounds of machines. However, over the past two centuries, the proliferation of steam and combustion engines and electronics have introduced new anthropogenic sounds into the environment (Pivato, 2011). As machine-generated sounds made their way through human society, from the workplace to the home and across the globe from agriculture to air and sea travel, machine-generated sounds have become a novel intrusive and detrimental affliction to human and environmental health (Goines and Hagler, 2007; Jerem and Mathews, 2021).

Consequently, the impact of machine-generated sounds on the environment has become an increasingly popular subject of investigation (Jerem and Mathews, 2021) with considerable evidence of its negative influence on animal behavior (Brumm and Slabbekoorn, 2005; Habib et al., 2007), community ecology (Francis et al., 2009), and species habitats (Nowacek et al., 2007; Barber et al., 2010; Chan et al., 2010; Slabbekoorn et al., 2010; Mullet et al., 2017a). Because of their human origin, machine-generated sounds fit within the ecoacoustics category of anthropophony, but more exclusively under the subcategory of technophony (Mullet et al., 2016). This separation is based on the difference between the biological and cultural sounds that humans have been making for millennia (e.g., music, song, 
language) with the more recent sounds generated by machine technology. Anthropophony of the former has evolved complex semiotic relationships in human societies and nature, while the latter generates sounds with generally no semiotic intent or relevance. This distinction is important because noise is an anthropocentric term often used to define machine sounds as unwanted sounds. This likely stems from how humans perceive the sonic relationship with the environment by distinguishing what is natural from what is unnatural in both human culture and ecologically (Booi and van den Berg, 2012; Gomes et al., 2021).

Because of this, it is vital to be aware that by using the term noise, without explicit definition, the researcher is inherently assuming the sonic element is also unwanted by their nonhuman animal subjects without providing evidence to support their assumptions. This results in implicit bias of a study's design and confounds ecological interpretation. Therefore, there must be a clear definition in the ecoacoustics literature for the word noise. We suggest that noise be generally defined as machinegenerated sound (technophony) that is unwanted or undesirable to humans. In this way, studies of "noise" impacts to wildlife must also clarify why or provide evidence that the variable of noise is "unwanted" to their study subjects (see Barber et al., 2010; Luo et al., 2015; Jerem and Mathews, 2021).

Conversely, technophony, as a distinct soundscape component, is an important contribution to acoustic habitats with significant ecological implications outside human perceptions (Mullet et al., 2017a). Similar to the soundscape component of biophony being ecologically distinguished by the sounds of soniferous species, technophony in the environment can also be distinguished by the presence of human technological sounds. Yet, technophonies cannot be reliably defined as unwanted sounds in non-human animals. The term noise (as defined above) does not adequately apply to the perspective of a non-human animal, but the term technophony still remains relevant. This is because non-human animals do not interpret the meanings of or differentiate between technophonic sources with the same semiotic mechanisms as the human originators. Nevertheless, the presence of technophony within the soundscape still plays an important role in animal behavioral ecology.

We recognize that technophony takes on a variety of characteristics in nature depending on its source. We propose three categorizes of technophony to generalize how it more commonly occurs in the environment. These categories include continuous technophony, ephemeral technophony, and abrupt technophony. Continuous technophony is characterized as constant machine-generated sound(s) in the environment, occurring over long temporal periods with little or no change. Some typical sources of continuous technophony include oil compressors, highway traffic, and airport traffic. Ephemeral technophony is not constant but occurs intermittently over temporal periods where environments experience a gap between machine-generated sound disturbance events. Ephemeral technophony sources include helicopter and airplane flybys, intermittent vehicle sounds on roads less-frequented than highways, and motorboats. Finally, abrupt technophony is derived from short temporal bursts of machine-generated sounds that do not persist over time. Examples of abrupt technophony sound sources are gunshots, explosions, and pile drivers. These three categories of technophony can also be applied to noise when presented from an anthropocentric perspective.

\section{Geophony}

Since the Earth and its atmosphere were formed 4 billion years ago, geophysical sounds have shaped the sonic environment. It was under these sonic conditions where the biological sounds of organisms in marine, freshwater, and terrestrial environments began their long and extensive process of evolution into the diverse animal orchestra we hear today. Concurrently, the Earth's own geomorphological evolution influenced the formation of sonic environments, acoustic habitats, and acoustic communities. It is reasonable to suggest that geophony is an inescapable, and integrated, semiotic component to the sonic environment, species evolution, and ecological processes. Because of this close relationship between biological organisms and geophysical sounds, it is inappropriate to combine geophony with noise without explicitly identifying the reasoning to do so. By dismissing the relevance of geophony in ecoacoustics studies or combining geophony with noise, one dismisses and misinterprets the fundamental nature of soundscapes and ecological relationships (Gomes et al., 2021).

Geophony has been clearly defined to be sounds generated by the Earth and its geophysical events (Pijanowski et al., 2011; Farina, 2014; Farina et al., 2021a). However, like technophony, geophony can be placed into three general categories that include continuous geophony, ephemeral geophony, and abrupt geophony. Continuous geophony includes those geophysical sounds that persist for long periods of time in the landscape. Perfect examples of continuous geophony include continuous free-flowing rivers and streams and sea waves. Ephemeral geophony consists of the geophysical sounds that do not persist in nature but occur intermittently over time, such as, the sounds of wind, rain, and ephemeral streams. Abrupt geophony are geophysical sound events that occur suddenly and in short time. Earthquakes, landslides, avalanches, and volcanic explosions are abrupt geophonic sound sources.

\section{Sonic Signature}

Sonotopes are distinct assortments of biophony, geophony, and technophony embedded within every portion of a land mosaic that vary in space, time, source, and intensity (Farina, 2014; Farina et al., 2021a). Such variability operates at different temporal and spatial scales and is sensed differently among species. In the presence of biophony, technophony, and certain geophony, each sonotope possesses a unique sonic ambience we call a sonic signature. We generally define sonic signature as the ever-present ambient sounds that form the sonic foundation of a sonotope. The sonic signature forms the primary occupied acoustic niche that soniferous species must sonically compete with in the most fundamental of ways (Figure 1). The Earth's primordial sonic signatures likely played significant roles in the evolution of animal sounds. The late Professor Stuart H. Gage (pers. comm. Michigan State University) described the sonic 


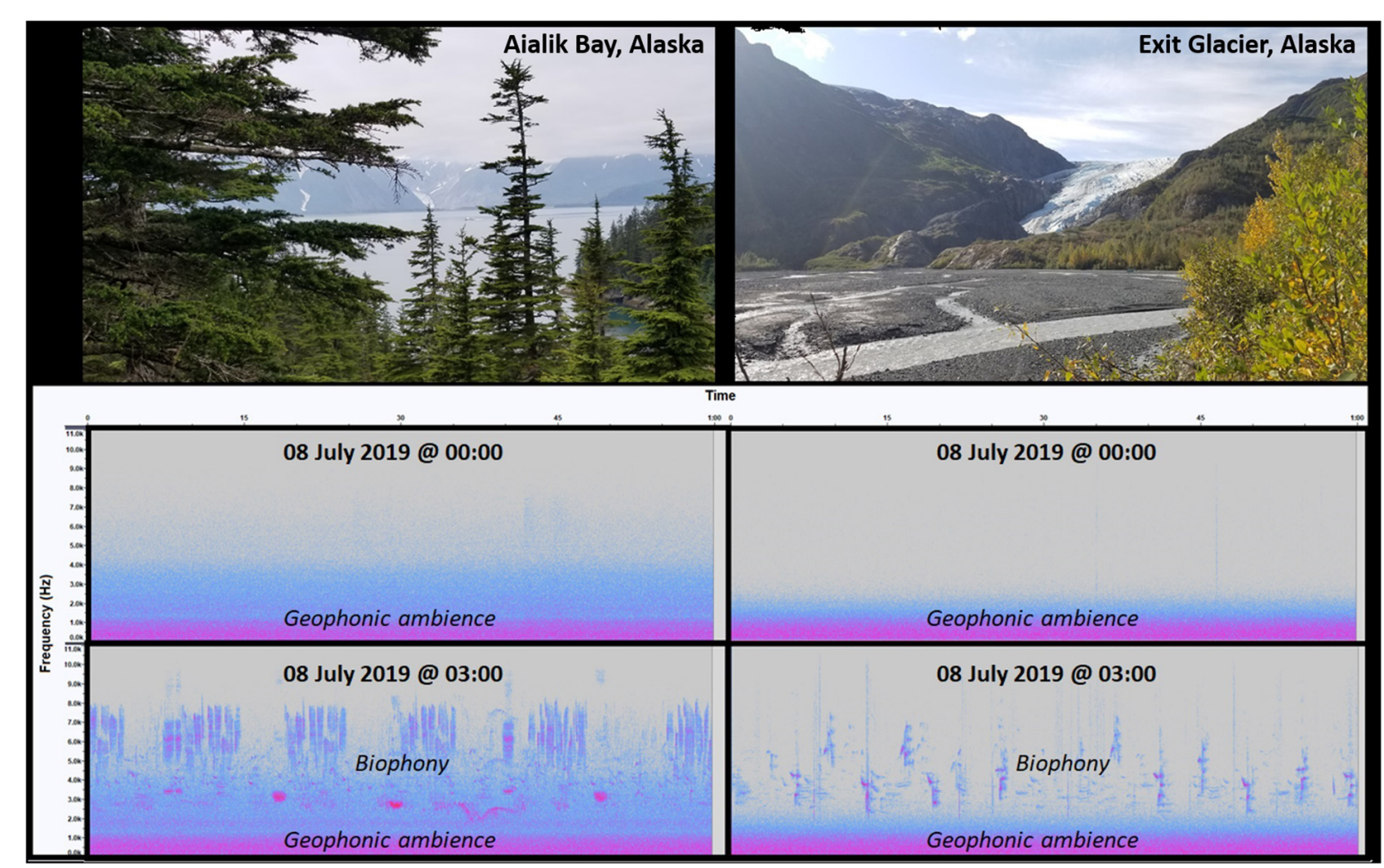

FIGURE 1 | Spectrogram comparison between two subarctic sonotopes located in Aialik Bay (coastal) (A) and Exit Glacier (interior) (B) of Kenai Fjords National Park in south-central Alaska $\left(60^{\circ} \mathrm{N} ; 150^{\circ} \mathrm{W}\right.$ ) on 08 July 2019 at 00:00 and 03:00, illustrating the presence of geophonic ambiences, respectively, characterized by the sounds of waves and a glacial creek, that occur in the absence of biophony, ephemeral/abrupt geophony, and anthropophony at 00:00 and in the presence of biophony during the dawn chorus at 03:00. Note that the geophonic ambience of the coastal sonotope possesses a different sonic signature given the range of low-frequency spectra than that at the interior sonotope, including differences in the intensity and composition of biophonies at higher frequencies between locations.

signature as the primeval sound of the Earth, the geophonic sounds that remain when all else is absent.

A sonic signature can be the result of a single or combination of sound sources (e.g., wind, running water, sea waves). The nature of a sonic signature determines its impact on the ecology of animals, all of which are species-specific. Based on this perspective, it is reasonable to hypothesize that the recurrent sounds of a sonotope's sonic signature have a role in the characterization and selection of a species' habitat (e.g., Tonolla et al., 2010, 2011; Mullet et al., 2017b; Decker et al., 2020; Linke et al., 2020) and therefore, provides a baseline of ambient sounds for a species' semiosis, as well as a quantifiable subject of ecoacoustics investigations (Putland et al., 2017).

Subarctic environments can exhibit periods of time when biophonies, technophony, and ephemeral/abrupt geophonies are not present within the acoustic space (Figure 1). In this case, there still exists an ambient background of lowfrequency, low-sound energy geophony that is continuous and ever-present. This phenomenon of geophonic ambience contrasts sharply with time periods when the acoustic space becomes occupied by biophonies, ephemeral/abrupt geophonies, and technophony but still remains a primary component of individual sonotopes (Figure 1). Thus, geophonic ambience creates a sonic signature that shapes the composition of acoustic habitats.

We acknowledge that sonic signatures are not exclusively geophysical sounds. In fact, the heavily developed metropolitan regions of the world possess a sonic signature of technophonic ambience often produced by vehicle traffic. Similarly, finerscaled urban sonotopes may have their own unique sonic signature depending on sound sources of the underlying ambience. Examples of these finer-scaled sonotopes are airports and manufacturing plants. Both geophony- and technophonybased sonic signatures are important ecological components to understanding biophonies and animal behavior.

\section{Distinguishing Noise From Geophony}

In order to understand the ecological role geophony plays in the environment, one must recognize the implications that research presents when combining geophony with technophony under the moniker of "noise." We have provided pragmatic reasons why geophony is not noise (i.e., unwanted sounds) in an ecological sense. However, we recognize that intense geophonic sources (e.g., waterfalls, torrents, sea waves) may be considered unwanted sounds from a human perspective, especially when assessing the acoustic qualities of an area for listening to biophonies. 
This highlights an important distinction to make when using the term noise to describe geophonies and technophonies. We first must acknowledge that the continuous and homogenous sounds of sonic signatures from a human perspective appear as uninformative "noise" but, in fact, the geophonic ambience of a sonotope most likely serves as a critical form of information in animal communication and habitat selection. Secondly, intense geophonic and technophonic sounds possess true and ecologically relevant attributes in the form of masking effects on certain sound sources. Masking can simply be described as one sound interfering with the detection of another sound. The ecological implications of this phenomenon have been demonstrated by the low-frequency sounds $(1-4 \mathrm{kHz})$ of roads and oil compressor fields effecting the ability of some organisms to hear vocalizing cohorts that call within the same frequency range (Ortega, 2012; Ortega and Francis, 2012). Intense geophonic sounds (e.g., high wind events) have also been problematic for detecting and discerning low-frequency biophonies (Mullet et al., 2016).

We suggest that researchers identify the types of geophony and technophony that may influence the results of their acoustic investigations. By doing so, the results of acoustic studies can be interpreted in the context of geophonies as a distinct sonic variable independent of technophony and as an ecological driver of species adaptations and evolution. We recommend that researchers avoid characterizing natural geophonic ambience as unwanted sound (i.e., environmental noise, ambient noise, background noise) (Codarin et al., 2009) for the purpose of avoiding confusion between an anthropocentric perception and one determined by animal semiotics. However, we recognize that animal avoidance behavior to technophony (Luo et al., 2015), geophony (Hayes and Huntly, 2005), and even biophony (Stanley et al., 2016) provides a rare opportunity to characterize some sound sources as unwanted sounds from an animal's perspective.

\section{Natural Quiet}

As noise expands to nearly every corner of the Earth, there has become increased interest to locate the world's quietest places (Cox, 2014). Only recently has natural quiet become a term used in bioacoustics and ecoacoustics literature (Mace et al., 2004; Votsi et al., 2014; Mullet et al., 2017b). Natural quiet is simply defined as a period of time when noise does not disturb natural sounds (Manning et al., 2007). This vague definition obviously suggests that natural quiet is composed of any form of biophony and geophony but also implies that there is some level of sound amplitude identified by some receiver as "quiet." More importantly, natural quiet, like noise, is a human construct. Humans easily identify natural sounds as separate from human sounds, but quiet lends itself to a more technical and often subjective definition we will not elaborate on here. Natural quiet within the human domain consists specifically of natural sounds identified according to non-human categories and quiet can be defined according to a relative measure of human perception (i.e., decibels) (e.g., Ambrose, 2006).

Natural quiet does not mean "silence," the complete absence of sound. Although uncommon in the literature, silence has been misused to describe natural sounds (Pfeifer et al., 2020) or used interchangeably with natural quiet (Hempton and Grossmann, 2009). The distinction between natural quiet and silence is important in order to avoid confusing audible-sensorial phenomena with the absence thereof. In fact, sounds are everpresent in nature because of the myriad of sound-producing interactions that occur at micro- and macro-scales of ecosystem processes (Smucker et al., 2006; Tornel et al., 2010; Fuller et al., 2015; Wall et al., 2017).

The sensitivity of a receiver to these sounds depends on their audible range of detection and the frequency and sound energy emitted by these processes. This suggests that sounds that occur outside a receiver's audible range are of less significance to its ecology than sounds they can hear. Yet, the frequency spectrum is not continuously occupied by sounds within a receiver's range of hearing. As illustrated in Figure 1, sounds are absent within a given frequency spectrum (e.g., 5,000-11,000 Hz) over a 1-min period at midnight (00:00). By definition, these vacant frequencies are silent to the receiver (i.e., SM4 Song Meter standard microphone, Wildlife Acoustics, Inc., Maynard Massachusetts) despite the microphones capability to detect sound events within this range. In this case, an argument can be made that silence does exist, but only in the context of the receiver. Therefore, the absence of sounds can be considered species-specific and unique by an individual's threshold of hearing. Unfortunately, this example is not what is insinuated as silence in the literature, nor is it considered to explain the sonic characteristics of natural quiet.

There has been some effort to measure natural quiet as a quantifiable variable (Lynch et al., 2011). This has stemmed from an interest in empirically characterizing undeveloped, wild landscapes in the context of human sonic experiences in nature. This approach emphasizes the anthropocentric perspective of what is considered natural (i.e., non-human sounds) and quiet (e.g., some baseline decibel level). Although this approach has benefited the preservation of natural soundscapes and expanded our understanding of human-nature connections through sound, natural quiet in this context provides very little relevance to understand ecological processes. We propose that the term natural quiet explicitly refer to the interpretation of a soundscape's acoustic qualities based on human perception and cultural definitions of "natural" and should not be applied to ecoacoustics studies intended to explain ecological processes where human perception is not the focus.

In an ecological context, it is important to acknowledge the absence of sounds within frequency spectra as an important characteristic of sonic environments. Regrettably, most bioacoustic and ecoacoustic studies have narrowly focused on the occupancy of multiple frequency spectra by biophony to describe the biodiversity of life in many parts of the world (Bertucci et al., 2016; Raynor et al., 2017; del Castillo Domínguez et al., 2021; Dröge et al., 2021; Farina et al., 2021b). Similarly, many studies have concentrated on the occupancy of acoustic partition to test the Acoustic Niche Hypothesis (Krause, 1993) as a viable explanation of sonic-animal ecology and evolution (Villanueva-Rivera, 2014; Bignotte-Giró and López-Iborra, 2019). However, the evidence of a "silent acoustic niche" 
(Figure 1) reverses the emphasis of interest to understand the sonic environment where the absence of biophony, geophony, and anthropophony are just as vital to understanding natural ecological processes. The opposing perspective of silent acoustic niches in the context of occupied acoustic niches is increasingly important as many ecosystems face catastrophic declines in biodiversity due to climate change, and human impacts (Krause et al., 2011; Krause and Farina, 2016). We recommend that more work be done on this subject.

\section{GEOPHONY AS A DRIVER OF ADAPTATION AND HABITAT SELECTION AND A COMPONENT OF ECOSYSTEMS}

Despite evidence that supports the effect geophonies have on the sonic behavior of marine (Brumm and Zollinger, 2011; Holt and Johnston, 2014; Guazzo et al., 2020; Helble et al., 2020) and terrestrial animal vocalizations (Brumm and Slater, 2006; Preininger et al., 2007; Brumm and Naguib, 2009; Samarra et al., 2009; Vargas-Salinas et al., 2014) and species evolution (Ryan and Brenowitz, 1985; Brumm and Slabbekoorn, 2005), there still exists a gap in our understanding the natural selection process of geophony in animal evolution, more specifically in terrestrial systems. Boeckle et al. (2009), for instance, found rockkipper frogs (Staurois latopalmatus) in habitats with continuous geophony from waterfalls emitted higher frequency calls and had smaller body sizes than cohorts where geophony was not as sonically pronounced. Zhao et al. (2017) demonstrated the role of geophony in mate selection among little torrent frogs (Amolops torrentis). They observed that females selected males that emitted higher frequency calls in areas where the geophony from streams had high sound amplitude. Males that emitted lower frequency calls in quieter environments were less likely to acquire a mate.

The literature that exists strongly suggests that geophony in marine and terrestrial systems has a significant role in the habitats animals select to inhabit in a landscape. It has been established that the composition and patterns of soundscapes are directly linked to the temporal and spatial arrangements of landscapes (Fuller et al., 2015; Mullet et al., 2016). Thus, sonotopes and their unique sonic signatures are essential components to the homogenous ecotopes that occur across the landscape. In this context, the temporal and spatial configuration of geophony is a fundamental sonic element of a species' habitat that exists within an ecotope. Mullet et al. (2017a) describe the ecological relationships between animal behavior and habitat selection in their seminal Acoustic Habitat Hypothesis.

Since geophony is generated by the vibrations of the physical environment (e.g., sound of wind from rustling leaves, sound of waves from the crashing of ocean water, sound of rain impacting vegetation); the sources, acoustic characteristics, and semiotics of geophony vary temporally and spatially depending on climatic conditions, geomorphology, and vegetation. As an example, the continuous geophony of a river will have differential sonic and semiotic significance based on the distance a sounddependent species is from the source. However, the manner in which geophony attenuates from the river is also dependent on the geomorphology and vegetation communities of the land surrounding it. In this case, geophony becomes subject to the composition and structure of the physical and biological environment creating unique sonotopes and acoustic habitats across a heterogenous, riparian landscape.

The many forms geophony can take in both its source and intensity are the consequences of complex geophysical phenomena. The characteristics of geophony across spatial scales can be influenced by elevation gradients, topography, global and microclimate dynamics, and successional stages of vegetation communities. Similarly, geophonies express temporal variation too, depending on its source (e.g., river sounds compared to rain showers), geographic region, time of day, and season. Some good examples of spatial and temporal differences in geophony are evident in the seasonal patterns of rainfall constituting the Amazon's wet and dry season (Sombroek, 2001) compared to the more extreme seasonal differences in geophony of south-central Alaska's boreal forests with rainy summers and actively flowing streams (Mullet, 2020) to winters with prolonged periods of ambient geophony interspersed with intense wind events over frozen lakes, rivers, and tundra (Mullet et al., 2016). The Amazon's wet season comes with increased geophony from rain but also marks the height of the breeding period for many songbirds that coincides with food availability (Stouffer et al., 2013). Similarly, the biophony of south-central Alaska increases considerably in summer months as the geophony of rushing water and rain dominate the soundscape (Mullet, 2020) while most soniferous species migrate or become dormant over winter (Mullet et al., 2016). These geophonically-related ecological processes are not only a product of geography, geomorphology, and vegetation, but their seasonality is also a result of the Earth's planetary tilt toward the Sun.

It is reasonable to hypothesize that the scale of ecological factors contributing to geophony are naturally integrated into the evolution and adaptation of animals and the dynamic complexities of Earth system processes. Subsequently, these relationships impact the manner in which sound-dependent species instinctually and cognitively select and occupy habitats. Even more so, the effects of anthropogenic climate change are having profound impacts on physical and biological systems (Rosenzweig et al., 2008). As a result, the attributes of geophonies at fine and coarse scales are likely changing temporally and spatially in a way that can alter the natural selection process they have on animal communities and species distributions. This underlines the importance of including geophony as a key subject in ecoacoustics studies.

\section{GUIDANCE FOR THE STUDY AND ANALYSIS OF GEOPHONY}

It is important for us to extend our competency of ecoacoustics in order to better understand the ecological resiliency of the sonic environment and its relationships to natural processes and human activity. As we have expressed earlier, the inclusion of geophony in ecoacoustics investigations is paramount to 
embodying a holistic knowledge of ecology. In fact, the full characterization of soundscapes can contribute to a greater breadth of knowledge than the narrow perspective of simply describing biophony or noise impacts to soniferous species and communities.

We are aware of the objective difficulties that exist to currently discern, measure, and evaluate geophony in ecoacoustic studies (see methods by Mullet et al., 2016). Nevertheless, including information concerning the characteristics and dynamics of geophonies in ecoacoustics greatly enhances the description of the sonic environment in which species operate and disclose their ecological relationships. To do this, it is necessary to create new, and improve on current, ecoacoustic tools that can be applied in ecoacoustics methodologies.

Geophonies, like many environmental sounds, can be efficiently detected and recorded using autonomous recording stations (ARS). This method enables a researcher to standardize their sample rate and recording intervals while allowing the recording device to run unattended for long-periods of time, generating a broad temporal sample of geophonic events. The temporal sampling period is dependent on the research question (see Buxton et al., 2016; Krause and Farina, 2016; Mullet et al., 2016, 2017b; Mullet, 2020 for examples), but we recommend 1min as a sufficient recording interval. Sonic data collected by ARS are often generated as a digital waveform (wav) file which can be processed into a metric or index using the computation of an algorithm suitable to answer the focused research question.

Geophonies are often characterized by more continuous patterns when compared to the ephemeral nature of biophonies, like bird calls. In fact, wind and rain events last longer than a few seconds or minutes compared with the short duration of bird calls. Only insects exhibit continuous biophonies but are typically discernable within a specific frequency spectra. Contrarily, geophonies often span a wide range of frequencies depending on the source and over longer time intervals $(30 \mathrm{~s}$ to hours). Their sonic patterns are typically more homogenous than most technophonies and biophonies. In order to adequately describe such processes, the frequential and temporal resolution with which data are analyzed should be fixed accordingly.

Few studies have approached the investigation of geophonies in terrestrial environments especially focusing on the capacity of ecoacoustic metrics to filter out geophonic events. Mullet et al. (2016) for instance, resolved to listening to thousands of sound recordings to parse out and quantify geophonies from biophonies and technophonies. This challenge has not been lost on other investigators (Bedoya et al., 2017; Sánchez-Giraldo et al., 2020). While terrestrial ecoacoustic studies have struggled with this issue in recent years, a more abundant literature testifies to the interest in and analysis of geophonies in marine systems that have measured the effect of rainfall (Medwin et al., 1992; Ma and Nystuen, 2005; Amitai and Nystuen, 2008; Ferroudj et al., 2014) and wind (Pensieri et al., 2015; Cauchy et al., 2018) on underwater sounds. While our expertise lies within terrestrial soundscapes and acoustic analyses applicable to these systems, we recognize that marine bioacoustics and ecoacoustics methods could prove useful.

Unlike studies that apply multiple acoustic indices to quantify and explain biophonies, we propose the Acoustic Complexity

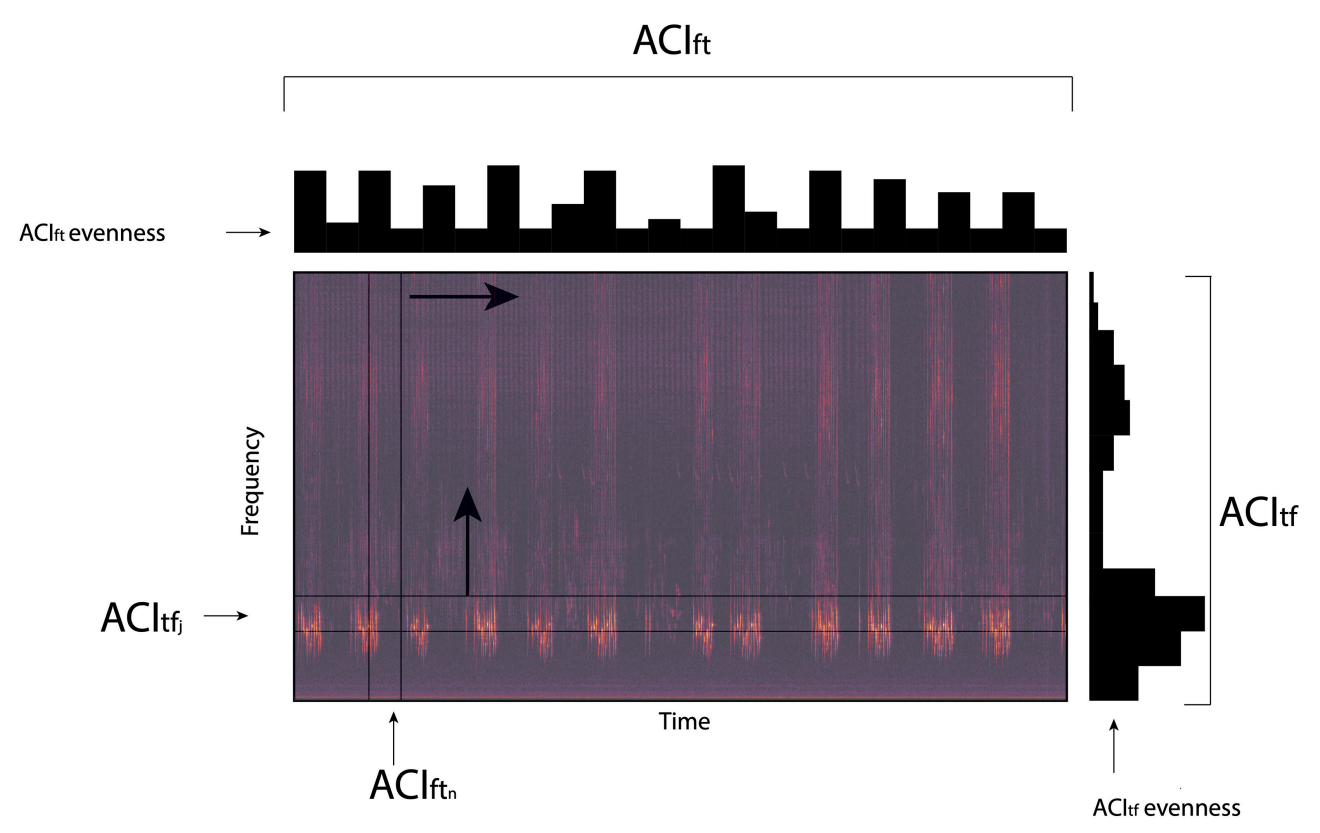

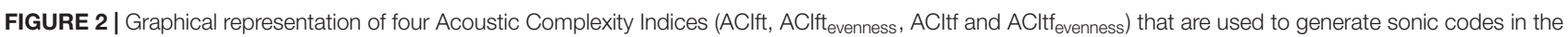
analysis of ecoacoustic events in a sound recording. AClft measures the sound energy across the frequency spectra within selected segments of time (AClftn), while

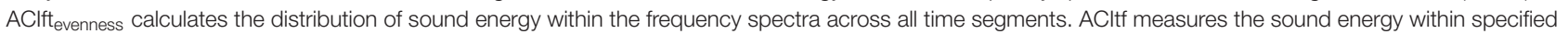
frequency intervals (ACltfj) across the recording period (time), while ACltf ${ }_{\text {evenness }}$ calculates the distribution of sound energy across all frequency intervals over the recording period. 
Indices (ACIs) (Pieretti et al., 2011; Farina et al., 2016) as a convenient set of metrics, powered by the recent SonoScape software ( $\mathrm{Li}$ and Farina, 2021) that operates at multiple scales, offering the possibility to sample sound recordings at different temporal resolutions to extract the ecoacoustic events of geophony and to filter sonic signals according to an energetic threshold.

In brief, the main performance of ACI enables the measures of sonic information based on the difference that occurs between successive intensity pitches and operates at every temporal scale of a sampling regime. Sonic energy can be measured across time for any frequency interval given the study's sample rate. Four $\mathrm{ACI}$ metrics $\left(\mathrm{ACI}_{\mathrm{tf}}, \mathrm{ACItf}_{\text {evenness }}, \mathrm{ACI}_{\mathrm{ft}}\right.$, and $\left.\mathrm{ACIft}_{\text {evenness }}\right)$ can be employed to measure sonic information across frequencies at any predetermined temporal interval (Li and Farina, 2021; Figure 2). In this way, $\mathrm{ACI}_{t f}$ measures the sonic information within a single frequency interval while $\mathrm{ACItf}_{\text {evenness }}$ calculates the distribution of $\mathrm{ACI}_{\mathrm{ft}}$ across multiple frequency intervals. The amount of sonic information included across frequencies is measured by $\mathrm{ACI}_{\mathrm{ft}}$ with $\mathrm{ACIft}_{\text {evenness }}$ used to calculate the distribution of $\mathrm{ACI}_{\mathrm{ft}}$ values along a specified temporal interval (Figure 2).

Geophonic events (e.g., an isolated gust of wind or period of rain) can be classified within the SonoScape software using the combination of $\mathrm{ACI}_{\mathrm{ft}}, \mathrm{ACIft}_{\text {evenness }}$ and $\mathrm{ACItf}_{\text {evenness }}$ that returns a sonic code that ranges from " 000 " to "999" (Farina et al., 2018). A sonic code of " 000 " is equivalent to "no sonic signal," whereas a sonic code of "999" represents a sonic signal that completely saturates the entire frequency spectra and time sequence. Heavy rain and strong wind events are often characterized by a sonic code of 999. Sonic codes are obtained for every time interval a wav file is sub-divided into.

For instance, if we process a wav file of $300 \mathrm{~s}$ at a resolution of 1 s, we obtain 300 codes, one for each second interval. If we reduce the temporal resolution to calculating indices at intervals of $6 \mathrm{~s}$, we obtain 50 codes, and so on. Sonic code values are strongly affected by the temporal resolution (i.e., time interval) chosen by the analyst because the temporal dimensions potentially delimit the field of existence of an ecoacoustic event. This is true if one desires to capture abrupt geophonic events like thunder. In this case, the sonic matrix must be appropriately segmented into intervals of 2-3 s for the event to be detected within the sonic code calculation. Similarly, the ephemeral geophony of wind or sea waves may require 10-30 s, while the continuous geophony of sonic signatures spread across long temporal scales. For rain, the time interval depends on whether the sonic events are shortor long-duration rain showers.

The usefulness of ACI for identifying, quantifying, and parsing out geophonies from biophonies and technophonies lends itself to the manner in which the indices of sonic events are calculated based on their occurrence within frequency spectra and over time intervals. The diverse, but unique, nature of geophonies can be relatively easy to distinguish from biophonies. However, we recognize that the similarities in sonic characteristics between sonic signatures of continuous geophony (e.g., rivers) and continuous technophony (e.g., highways) or the ephemeral occurrence of intermittent passing cars at less-traveled roadways and wind events may confuse ACI results. More investigation is underway to address these issues. Although we recognize that other scientists are addressing the issues of geophony in acoustic analysis (Bedoya et al., 2017; Sánchez-Giraldo et al., 2020), there appears to be open opportunities to explore ACI beyond biophonies to measure and quantitatively interpret geophonies within sonic environments.

\section{CONCLUSION}

The geophonies of Earth have been an evolutionary driver of animal physiology and communication across a diverse array of extant and extinct species. Given their ever-present influence on the sonic environment, animal behavior, and human experience, we suggest that geophonies must occupy a more central position in the study and understanding of ecological processes. This is even more important now that the expansive impacts of anthropogenic climate change to the Biosphere present exceptional risks to displacing and reconfiguring sonic events, if not driving many soundscapes to extinction (Sueur et al., 2019). Among these are certainly the geophonies that are directly associated with Earth's processes. Unfortunately, these changes have already begun, and we must strive to obtain a higher standard of ecoacoustics research (Krause and Farina, 2016).

As we currently explore the surface of Mars (Leighton, 2021), we have acquired the first recordings of Martian geophony. This scientific achievement may give us insights to the role geophony has played in Earth's primordial history, or perhaps, a peak into Earth's distant future. Our pursuit of knowledge to understand the ecology of our own world must not negate the fundamental elements and phenomena that have shaped its existence. The quest to understand geophony among the myriad of biological and anthropogenic sounds can only open new doors to discovery here on Earth. We invite further research on this subject to generate a more holistic understanding of their semiotic relationships.

\section{DATA AVAILABILITY STATEMENT}

The raw data supporting the conclusions of this article will be made available by the authors, without undue reservation.

\section{AUTHOR CONTRIBUTIONS}

AF and TM developed the theoretical basis of this manuscript and contributed equally to the literature review, writing, and revisions of the manuscript. TB, DB, and TT provided institutional support and the motivation to develop and publish this work. PL contributed to technical support for data processing. All authors contributed to the successful completion and publication of this article and collectively approved the submitted version.

\section{FUNDING}

Any funding that contributed to this article was provided by the U.S. National Park Service and Urbino University. 


\section{ACKNOWLEDGMENTS}

We are thankful to J. M. Morton for the many discussions he had with T. C. Mullet on the ecological role of geophony, noise, and natural quiet in Alaska. We also acknowledge the support of Kenai National Wildlife Refuge, Kenai Fjords National Park, University of Alaska Fairbanks, and University of Urbino that was given to the research that initiated the development

\section{REFERENCES}

Ambrose, R. E. (2006). Sound Levels in the Primary Vegetation Types in Grand Canyon National Park, July 2005. Castle Valley: Sandhill Company.

Amitai, E., and Nystuen, J. A. (2008). "Underwater acoustic measurements of rainfall," in Precipitation: Advances in Measurement, Estimation and Prediction, ed. S. Michaelides (Berlin: Springer), 343-363.

Barber, J. R., Crooks, K. R., and Fristrup, K. M. (2010). The costs of chronic noise exposure for terrestrial organisms. Trends Ecol. Evol. 25, 180-189. doi: 10.1016/j.tree.2009.08.002

Barr, J. (1972). Man and nature - the ecological controversy and the Old Testament. Bull. John Rylands Libr. 55, 9-32. doi: 10.7227/bjrl.55.1.2

Bedoya, C., Isaza, C., Daza, J. M., and López, J. D. (2017). Automatic identification of rainfall in acoustic recordings. Ecol. Indic. 75, 95-100.

Bertucci, F., Parmentier, E., Lecellier, G., Hawkins, A. D., and Lecchini, D. (2016). Acoustic indices provide information on the status of coral reefs: an example from Moorea Island in the South Pacific. Sci. Rep. 6:33326. doi: 10.1038/ srep33326

Bignotte-Giró, I., and López-Iborra, G. M. (2019). Acoustic niche partitioning in five Cuban frogs of the genus Eleutherodactylus. Amphib. Reptilia 40, 1-11. doi: 10.1163/15685381-17000170

Boeckle, M., Preininger, D., and Hödl, W. (2009). Communication in noisy environments I: acoustic signals of Staurois latopalmatus Boulenger 1887. Herpetologica 65 , 154-165.

Booi, H., and van den Berg, F. (2012). Quiet areas and the need for quietness in Amsterdam. Int. J. Environ. Res. Public Health 9, 1030-1050. doi: 10.3390/ ijerph9041030

Botteldooren, D., De Coensel, B., and De Muer, T. (2006). The temporal structure of urban soundscapes. J. Sound Vib. 292, 105-123. doi: 10.1016/j.jsv.2005.07.026

Brumm, H. (2010). “Anthropogenic noise: implications for conservation," in Encyclopedia of Animal Behavior, eds M. Breed and J. Moore (Oxford: Oxford Academic Press), 89-93.

Brumm, H., and Naguib, M. (2009). Environmental acoustics and the evolution of bird song. Adv. Stud. Behav. 40, 1-33. doi: 10.1016/s0065-3454(09)40001-9

Brumm, H., and Slabbekoorn, H. (2005). Acoustic communication in noise. $A d v$. Stud. Behav. 35, 151-209.

Brumm, H., and Slater, P. J. B. (2006). Ambient noise, motor fatigue, and serial redundancy in chaffinch song. Behav. Ecol. Sociobiol. 60, 475-481. doi: 10.1007/ s00265-006-0188-y

Brumm, H., and Zollinger, S. A. (2011). The evolution of the Lombard effect: 100 years of psychoacoustic research. Behaviour 148, 1173-1198. doi: 10.1163/ $000579511 \times 605759$

Bunkley, J. P., McClure, J. W., Kleist, N., Francis, C. D., and Barber, J. R. (2015). Anthropogenic noise alters bat activity levels and echolocation calls. Glob. Ecol. Conserv. 3, 62-71. doi: 10.1016/j.gecco.2014.11.002

Buxton, R. T., Brown, E., Sharman, L., Gabriele, C. M., and McKenna, M. F. (2016). Using bioacoustics to examine shifts in songbird phenology. Ecol. Evol. 6, 4697-4710. doi: 10.1002/ece3.2242

Cauchy, P., Heywood, K. J., Merchant, N. D., Queste, B. Y., and Testor, P. (2018). Wind speed measured from underwater gliders using passive acoustics. J. Atmosph. Ocean. Technol. 35, 2305-2321. doi: 10.1175/jtech-d-170209.1

Chan, A. A. Y., Giraldo-Perez, P., Smith, S., and Blumstein, D. T. (2010). Anthropogenic noise effects risk assessment and attention: the distracted prey hypothesis. Biol. Lett. 6, 458-461. doi: 10.1098/rsbl.2009. 1081 of the authors' perspectives on this subject. We are thankful for the outstanding support of the International Society of Ecoacoustics who provide understanding of the importance of this work. Finally, we acknowledge the profound contributions that Stuart H. Gage made to the development of this work when he was alive and his lasting legacy on the subject of ecoacoustics.

- Staff of Kenai Fjords National Park

Codarin, A., Wysocki, L. E., Ladich, F., and Picciulin, M. (2009). Effects of ambient and boat noise on hearing and communication in three fish species living in a marine protected area (Miramare, Italy). Mar. Pollut. Bull. 58, 1880-1887. doi: 10.1016/j.marpolbul.2009.07.011

Cox, T. (2014). The Sound Book: The Science Of The Sonic Wonders Of The World. New York: WW Norton \& Company.

Decker, E., Parker, B., Linke, S., Capon, S., and Sheldon, F. (2020). Singing streams: describing freshwater soundscapes with the help of acoustic indices. Ecol. Evol. 10, 4979-4989. doi: 10.1002/ece3.6251

del Castillo Domínguez, S. L., González, C. A. M., Fernández, E. B., Pelea, L. P., Cézilly, F., and Bosch, R. A. (2021). Predicting the invasion of the acoustic niche: potential distribution and call transmission efficiency of a newly introduced frog in Cuba. Persp. Ecol. Conserv. 19, 90-97. doi: 10.1016/j.pecon.2020.12.002

Dröge, S., Martin, D. A., Andriafanomezantsoa, R., Burivalova, Z., Fulgence, T. R., Osen, K., et al. (2021). Listening to a changing landscape: acoustic indices reflect bird species richness and plot-scale vegetation structure across different landuse types in north-eastern Madagascar. Ecol. Indic. 120:106929. doi: 10.1016/j. ecolind.2020.106929

Farina, A. (2014). Soundscape Ecology. Dordrecht: Springer.

Farina, A., Eldridge, A., and Li, P. (2021a). Ecoacoustics and multispecies semiosis: naming, semantics, semiotic characteristics, and competencies. Biosemiotics 14, 141-165. doi: 10.1007/s12304-021-09402-6

Farina, A., Righini, R., Fuller, S., Li, P., and Pavan, G. (2021b). Acoustic complexity indices reveal the acoustic communities of the old-growth Mediterranean forest of Sasso Fratino Integral Natural Reserve (Central Italy). Ecol. Indic. 120:106927. doi: 10.1016/j.ecolind.2020.106927

Farina, A., and Gage, S. H. (2017). Ecoacoustics: The Ecological Role of Sounds. Hoboken: Wiley.

Farina, A., Gage, S. H., and Salutari, P. (2018). Testing the ecoacoustics event detection and identification (EEDI) approach on Mediterranean soundscapes. Ecol. Indic. 85, 698-715. doi: 10.1016/j.ecolind.2017.10.073

Farina, A., and Li, P. (2021). Methods in Ecoacoustics: The Acoustic Complexity Index. Berlin: Springer.

Farina, A., Pieretti, N., Salutari, P., Tognari, E., and Lombardi, A. (2016). The application of the acoustic complexity indices (ACI) to ecoacoustic event detection and identification (EEDI) modeling. Biosemiotics 9, 227-246. doi: 10.1007/s12304-016-9266-3

Ferroudj, M., Truskinger, A., Towsey, M., Zhang, L., Zhang, J., and Roe, P. (2014). "Detection of rain in acoustic recordings of the environment," in Proceedings of the 13th Pacific Rim International Conference on Artificial Intelligence (Cham: Springer), 104-116

Francis, C. D., Ortega, C. P., and Cruz, A. (2009). Noise pollution changes avian communities and species interactions. Curr. Biol. 19, 1415-1419. doi: 10.1016/ j.cub.2009.06.052

Fuller, S., Axel, A. C., Tucker, D., and Gage, S. H. (2015). Connecting soundscape to landscape: which acoustic index best describes landscape configuration? Ecol. Indic. 58, 207-215. doi: 10.1016/j.ecolind.2015.05.057

Gage, S. H., and Farina, A. (2017). Ecoacoustics: The Ecological Role of Sounds. Hoboken: Wiley.

Goines, L., and Hagler, L. (2007). Noise pollution: a modern plague. South. Med. J. 100, 287-294. doi: 10.1097/smj.0b013e3180318be5

Gomes, D. G. E., Francis, C. D., and Barber, J. R. (2021). Using the past to understand the present: coping with natural and anthropogenic noise. Bioscience 71, 223-234. doi: 10.1093/biosci/biaa161

Guazzo, R. A., Helble, T. A., Alongi, G. C., Durbach, I. N., Martin, C. R., Martin, S. W., et al. (2020). The Lombard effect in singing humpback whales: source 
levels increase as ambient ocean noise levels increase. J. Acoust. Soc. Am. 148, 542-555. doi: 10.1121/10.0001669

Habib, L., Bayne, E. M., and Boutin, S. (2007). Chronic industrial noise affects pairing success and age structure of ovenbirds Seiurus aurocapilla. J. Appl. Ecol. 44, 176-184. doi: 10.1111/j.1365-2664.2006.01234.x

Hayes, A. R., and Huntly, N. J. (2005). Effects of wind on the behavior and call transmission of pikas (Ochotona princeps). J. Mammal. 86, 974-981. doi: 10. 1644/1545-1542(2005)86[974:eowotb]2.0.co;2

Helble, T. A., Guazzo, R. A., Martin, C. R., Durbach, I. N., Alongi, G. C., Martin, S. W., et al. (2020). Lombard effect: minke whale boing call source levels vary with natural variations in ocean noise. J. Acoust. Soc. Am. 147, 698-712. doi: 10.1121/10.0000596

Hempton, G., and Grossmann, J. (2009). One Square Inch of Silence: One Man's Search For Natural Silence In A Noisy World. New York: Simon and Schuster.

Holt, D. E., and Johnston, C. E. (2014). Evidence of the Lombard effect in fishes. Behav. Ecol. 25, 819-826. doi: 10.1093/beheco/aru028

IPCC (2021). Climate Change Widespread, Rapid, and Intensifying. Available Online at: https://www.ipcc.ch/2021/08/09/ar6-wg1-20210809-pr/ (accessed September 15, 2021).

Jerem, P., and Mathews, F. (2021). Trends and knowledge gaps in field research investigating effects of anthropogenic noise. Conserv. Biol. 35, 115-129. doi: 10.1111/cobi. 13510

Kight, C. R., and Swaddle, J. P. (2011). How and why environmental noise impacts animals: an integrative, mechanistic review. Ecol. Lett. 14, 1052-1061. doi: 10.1111/j.1461-0248.2011.01664.x

Klump, G. M. (1996). "Bird communication in the noisy world," in Ecology and Evolution of Acoustic Communication in Birds, eds D. E. Kroodsma and E. H. Miller (New York: Cornell University Press), 321-338. doi: 10.7591/ 9781501736957-026

Koper, R. P., and Plön, S. (2012). The Potential Impacts of Anthropogenic Noise on Marine Animals and Recommendations for Research in South Africa. EWT Research and Technical Paper No. 1. Midrand: Endangered Wildlife Trust.

Krause, B., and Farina, A. (2016). Using ecoacoustic methods to survey the impacts of climate change on biodiversity. Biol. Conserv. 195, 245-254. doi: 10.13287/j. 1001-9332.202103.032

Krause, B. L. (1993). The niche hypothesis: a virtual symphony of animal sounds, the origins of musical expression and the health of habitats. Soundsc. Newslett. 6, 6-10.

Krause, B. L., Gage, S. H., and Joo, W. (2011). Measuring and interpreting the temporal variability in the soundscape at four places in Sequoia National Park. Landsc. Ecol. 26, 1247-1256. doi: 10.1007/s10980-011-9639-6

Leighton, T. (2021). Thoughts on the sounds of Mars from NASA's Mars perseverance. Acoust. Bull. 45, 22-28.

Li, P., and Farina, A. (2021). "Introduction to the SonoScape, an open-source software application in MatLab," in Methods in Ecoacoustics: The Acoustic Complexity Index, eds A. Farina and P. Li (Berlin: Springer).

Linke, S., Decker, E., Gifford, T., and Desjonquères, C. (2020). Diurnal variation in freshwater ecoacoustics: implications for site-level sampling design. Freshw. Biol. 65, 86-95. doi: 10.1111/fwb.13227

Luo, J., Seimers, B., and Koselj, K. (2015). How anthropogenic noise affects foraging. Glob. Change Biol. 21, 3278-3289.

Luther, D., and Gentry, K. (2013). Sources of background noise and their influence on vertebrate acoustic communication. Behaviour 150, 1045-1068.

Lynch, E., Joyce, D., and Fristrup, K. (2011). An assessment of noise audibility and sound levels in US National Parks. Landsc. Ecol. 26, 1297-1309.

Ma, B. B., and Nystuen, J. A. (2005). Passive acoustic detection and measurement of rainfall at sea. J. Atmosph. Ocean. Technol. 22, 1225-1248. doi: 10.1121/1. 2871485

Mace, B. L., Bell, P. A., and Loomis, R. J. (2004). Visibility and natural quiet in national parks and wilderness areas: psychological considerations. Environ. Behav. 36, 5-31. doi: 10.1177/0013916503254747

Manning, R., Newman, P., Barber, J., Monz, C., Hallo, J., and Lawson, S. (2018). Principles for studying and managing natural quiet and natural darkness in national parks and other protected areas. George Wright Forum 35, 350-362.

Manning, R., Valliere, W., Hallo, J., Newman, P., Pilcher, E., Savidge, M., et al. (2007). "From landscapes to soundscapes: understanding and managing natural quiet in the national parks," in Proceedings of the 2006 Northeastern Recreation
Research Symposium, eds R. Burns and K. Robinson (Newtown Square: US Department of Agriculture, Forest Service, Northern Research Station), 601-606.

Medwin, H., Nystuen, J. A., Jacobus, P. W., Ostwald, L. H., and Snyder, D. E. (1992). The anatomy of underwater rain noise. J. Acoust. Soc. Am. 92, 1613-1623. doi: $10.1121 / 1.403902$

Mullet, T. C. (2020). An ecoacoustics snapshot of a subarctic coastal wilderness: Aialik Bay Alaska. J. Ecoacoust. 4:2. doi: 10.35995/jea4010002

Mullet, T. C., Farina, A., and Gage, S. H. (2017a). The acoustic habitat hypothesis: an ecoacoustics perspective on species habitat selection. Biosemiotics 10, 319-336.

Mullet, T. C., Morton, J. M., Gage, S. H., and Huettmann, F. (2017b). Acoustic footprint of snowmobile noise and natural quiet refugia in an Alaskan wilderness. Nat. Areas J. 37, 332-349. doi: 10.3375/043.037.0308

Mullet, T. C., Gage, S. H., Morton, J. M., and Huettmann, F. (2016). Temporal and spatial variation of a winter soundscape in south-central Alaska. Landsc. Ecol. 31, 1117-1137.

Nowacek, D. P., Thorne, L. H., Johnston, D. W., and Tyack, P. L. (2007). Responses of cetaceans to anthropogenic noise. Mammal Rev. 37, 81-115. doi: 10.1111/j. 1365-2907.2007.00104.x

Ortega, C. P. (2012). Effects of noise pollution on birds: a brief review of our knowledge. Ornithol. Monogr. 74, 6-22. doi: 10.1525/om.2012.74.1.6

Ortega, C. P., and Francis, C. D. (2012). Effects of gas-well-compressor noise on the ability to detect birds during surveys in northwest New Mexico. Ornithol. Monogr. 74, 78-90.

Pensieri, S., Bozzano, R., Nystuen, J. A., Anagnostou, E. N., Anagnostou, M. N., and Bechini, R. (2015). Underwater acoustic measurements to estimate wind and rainfall in the Mediterranean Sea. Adv. Meteorol. 2015:612512.

Pfeifer, E., Fiedler, H., and Wittmann, M. (2020). Increased relaxation and present orientation after a period of silence in a natural surrounding. Nordic J. Music Ther. 29, 75-92. doi: 10.1080/08098131.2019.1642374

Pieretti, N., Farina, A., and Morri, D. (2011). A new methodology to infer the singing activity of an avian community: the Acoustic Complexity Index (ACI). Ecol. Indic. 11, 868-873. doi: 10.1016/j.ecolind.2010.11.005

Pijanowski, B. C., Farina, A., Gage, S. H., Dumyahn, S. L., and Krause, B. L. (2011). What is soundscape ecology? An introduction and overview of an emerging new science. Landsc. Ecol. 26, 1213-1232.

Pivato, S. (2011). Il secolo del rumore. Il paesaggio sonoro nel Novecento. Bologna: Società Editrice Il Mulino, 1-179.

Preininger, D., Böckle, M., and Hödl, W. (2007). Comparison of anuran acoustic communities of two habitat types in Danum Valley conservation area, Sabah, Malaysia. Salamandra 43, 129-138.

Putland, R. L., Constantine, R., and Radford, C. A. (2017). Exploring spatial and temporal trends in the soundscape of an ecologically significant embayment. Sci. Rep. 7:5713. doi: 10.1038/s41598-017-06347-0

Raynor, E. J., Whalen, C. E., Brown, M. B., and Powell, L. A. (2017). Grassland bird community and acoustic complexity appear unaffected by proximity to a wind energy facility in the Nebraska Sandhills. Condor Ornithol. Appl. 119, 484-496.

Rosenzweig, C., Karoly, D., Vicarelli, M., Neofotis, P., Wu, Q., Casassa, G., et al. (2008). Attributing physical and biological impacts to anthropogenic climate change. Nature 453, 353-357. doi: 10.1038/nature06937

Ryan, M. J., and Brenowitz, E. A. (1985). The role of body size, phylogeny, and ambient noise in the evolution of bird song. Am. Nat. 126, 87-100. doi: 10 . $1086 / 284398$

Samarra, F. I. P., Klappert, K., Brumm, H., and Miller, P. J. O. (2009). Background noise constrains communication: acoustic masking of courtship song in the fruit fly Drosophila montana. Behaviour 146, 1635-1648. doi: 10.1163/ 156853909x463713

Sánchez-Giraldo, C., Bedoya, C. L., Morán-Vásquez, R. A., Isaza, C. V., and Daza, J. M. (2020). Ecoacoustics in the rain: understanding acoustic indices under the most common geophonic source in tropical rainforests. Rem. Sens. Ecol. Conserv. 6, 248-261.

Shannon, G., McKenna, M. F., Angeloni, L. M., Crooks, K. R., Fristrup, K. M., Brown, E., et al. (2016). A synthesis of two decades of research documenting the effects of noise on wildlife. Biol. Rev. 91, 982-1005. doi: 10.1111/brv.12207

Slabbekoorn, H., Bouton, N., van Opzeeland, I., Coers, A., ten Cate, C., and Popper, A. N. (2010). A noisy spring: the impact of globally rising underwater sound levels on fish. Trends Ecol. Evol. 25, 419-427. doi: 10.1016/j.tree.2010.04.005 
Smucker, A., Park, E. J., Quintanilla, M., Gage, S., and Bird, G. (2006). “Acoustical profile identification of soil hydration and stability," in Proceedings of the ASA-CSSA-SSSA International Annual Meetings (November 12-16, 2006), Indianapolis, IN.

Sombroek, W. G. (2001). Spatial and temporal patterns of Amazon rainfall. Ambio 30, 388-396. doi: 10.1579/0044-7447-30.7.388

Stanley, C. Q., Walter, M. H., Venkatraman, M. X., and Wilkinson, G. S. (2016). Insect noise avoidance in the dawn chorus of Neotropical birds. Anim. Behav. 112, 255-265. doi: 10.1016/j.anbehav.2015.12.003

Stouffer, P. C., Johnson, E. I., and Bierregaard, R. O. Jr. (2013). Breeding seasonality in central Amazonian rainforest birds. Auk 130, 529-540. doi: 10.1525/auk. 2013.12179

Sueur, J., and Farina, A. (2015). Ecoacoustics: the ecological investigation and interpretation of environment sound. Biosemiotics 8, 493-502.

Sueur, J., Krause, B., and Farina, A. (2019). Climate change is breaking earth's beat. Trends Ecol. Evol. 34, 971-973. doi: 10.1016/j.tree.2019.07.014

Tafalla, R. J., and Evans, G. W. (1997). Noise, physiology, and human performance: the potential role of effort. J. Occup. Health Psychol. 2, 148-55.

Tonolla, D., Acuña, V., Lorang, M. S., Heutschi, K., and Tockner, K. (2010). A fieldbased investigation to examine underwater soundscapes of five common river habitats. Hydrol. Process. 24, 3146-3156. doi: 10.1002/hyp.7730

Tonolla, D., Lorang, M. S., Heutschi, K., Gotschalk, C. C., and Tockner, K. (2011). Characterization of spatial heterogeneity in underwater soundscapes at the river segment scale. Limnol. Oceanogr. 56, 2319-2333. doi: 10.4319/lo.2011.56.6. 2319

Tornel, M. Q., Bird, G., and Gage, S. (2010). Impact of microwaves and water on acoustical signatures of yard and kitchen refuse compost. Comp. Sci. Utiliz. 18, 140-144. doi: 10.1080/1065657x.2010.10736949

United Nations [UN] (2019b). UN Report: Nature's Dangerous Decline 'Unprecedented'; Species Extinction Rates 'Accelerating'. Available Online at: https:/www.un.org/sustainabledevelopment/blog/2019/05/nature-declineunprecedented-report/ (accessed September 15, 2021).

United Nations [UN] (2019a). Global Resources Outlook 2019. Nairobi: United Nations Environment Program.

Vargas-Salinas, F., Dorado-Correa, A., and Amézquita, A. (2014). Microclimate and stream noise predict geographic divergence in the auditory signal of a threatened poison frog. Biotropica 46, 748-755.
Villanueva-Rivera, L. J. (2014). Eleutherodactylus frogs show frequency but no temporal partitioning: implications for the acoustic niche hypothesis. PeerJ 2:e496. doi: 10.7717/ peerj.496

Votsi, N.-E. P., Mazaris, A. D., Kallimani, A. S., and Pantis, J. D. (2014). Natural quiet: an additional feature reflecting green tourism development in conservation areas of Greece. Tour. Manag. Persp. 11, $10-17$.

Wall, C. C., Mann, D. A., Lembke, C., Taylor, C., He, R., and Kellison, T. (2017). Mapping the soundscape off the southeastern USA by using passive acoustic glider technology. Mar. Coast. Fish. 9, 23-37. doi: 10.1080/19425120.2016. 1255685

Xie, J., Hu, K., Zhu, M., and Guo, Y. (2020). Data-driven analysis of global research trends in bioacoustics and ecoacoustics from 1991 to 2018. Ecol. Inform. 57:101068.

Zhao, L., Zhu, B., Wang, J., Brauth, S. E., Tang, Y., and Cui, J. (2017). Sometimes noise is beneficial: stream noise informs vocal communication in the little torrent frog Amolops torrentis. J. Ethol. 35, 259-267. doi: 10.1007/s10164-0170515-y

Conflict of Interest: The authors declare that the research was conducted in the absence of any commercial or financial relationships that could be construed as a potential conflict of interest.

Publisher's Note: All claims expressed in this article are solely those of the authors and do not necessarily represent those of their affiliated organizations, or those of the publisher, the editors and the reviewers. Any product that may be evaluated in this article, or claim that may be made by its manufacturer, is not guaranteed or endorsed by the publisher.

Copyright (c) 2021 Farina, Mullet, Bazarbayeva, Tazhibayeva, Bulatova and Li. This is an open-access article distributed under the terms of the Creative Commons Attribution License (CC BY). The use, distribution or reproduction in other forums is permitted, provided the original author(s) and the copyright owner(s) are credited and that the original publication in this journal is cited, in accordance with accepted academic practice. No use, distribution or reproduction is permitted which does not comply with these terms. 